\title{
Numerical Study of a Thermosyphon Cooling System: film condensation
}

\author{
Filian Arbiyani ${ }^{1}$ \\ ${ }^{1}$ Department of Mechanical Engineering, Universitas Katolik Indonesia Atma Jaya, Jakarta, Indonesia \\ f.arbiyani@atmajaya.ac.id
}

\begin{abstract}
Studies of condensation in several cooling systems have been conducted. However, the mode of condensation in two-phase cooling systems to achieve a high rate of condensation in compact devices has not been explored. Condensation phenomena, indeed, is a key parameter in designing a thermosyphon water cooled condenser system. The analysis of this condensation phenomena has been done numerically by implementing the governing equations and boundary conditions in commercial MATLAB software. Steady-state laminar film condensation on the radial system is assumed as a condensation phenomenon between vapor and the outer surface of coolant coil. There is a good agreement between experimental and simulation results. Furthermore, for $0.3 \mathrm{LPM} 10{ }^{\circ} \mathrm{C}$, it is found the standard deviation of $0.3 \%$. This small standard deviation indicates the good accuracy of the simulation. At a constant mass flow rate of water, the higher inlet water temperature will result in a higher Nusselt number of water. Furthermore, at the same Nusselt number of water, the lower inlet water temperature obtained a higher film condensation rate. Nusselt number of film condensation increases as the Nusselt number of water decreases at the various constant of mass flow rate of water. Additionally, the lower inlet water temperature will result in a lower Nusselt number of water. The value of Reynold number film condensation increases as Reynold numbers and Nusselt number of water increase. At various constant mass flow rates of the water, at the same Nusselt number of water, the Reynold number of film condensation increases with lower inlet water temperature. The lower inlet water temperature increases the value of Reynold number of film condensation leading to more wavy and turbulent flow. The present study provides guidelines for thermal management engineers to design and fabricate compact cooling systems. Keywords-film condensation; thermosyphon; numerical study; two-phase cooling system; MATLAB
\end{abstract}

\section{Introduction}

Studies of condensation in several cooling systems have been conducted. However, the mode of condensation in two-phase cooling systems to achieve a high rate of condensation in compact devices has not been explored. Condensation phenomena, indeed, is a key parameter in designing a thermosyphon water cooled condenser system. Since it is difficult to attain a drop-wise condensation, which has higher heat transfer coefficient, and since there was no enhancement structure in the outer condenser wall, thus film condensation was assumed in the fundamental research of the present study.

\section{Material and Method}

\subsection{Governing Equation and Boundary Conditions}

Studies of condensation in several cooling systems have been conducted. However, the mode of condensation in two-phase cooling systems to achieve a high rate of condensation in compact devices has not been explored. Condensation phenomena, indeed, is a key parameter in designing a thermosyphon water cooled condenser system. Since it is difficult to attain a drop-wise condensation, which has higher heat transfer coefficient, and since there was no enhancement structure in the outer condenser wall, thus film condensation was assumed in the fundamental research of the present study.

Steady-state laminar film condensation on the radial system (Fig.2) is assumed as a condensation phenomenon between vapor and the outer surface of coolant coil [1]. The governing equations of the pressure drop simulation model of thermosyphon system are the equations of the net driving head caused by the difference between the density of the liquid in the downcomer and that of the vapor/liquid mixture in the riser, which is expressed in equation (1):

$$
\frac{d p}{d z}=\frac{d p_{f}}{d z}+\frac{d p_{g}}{d z}
$$




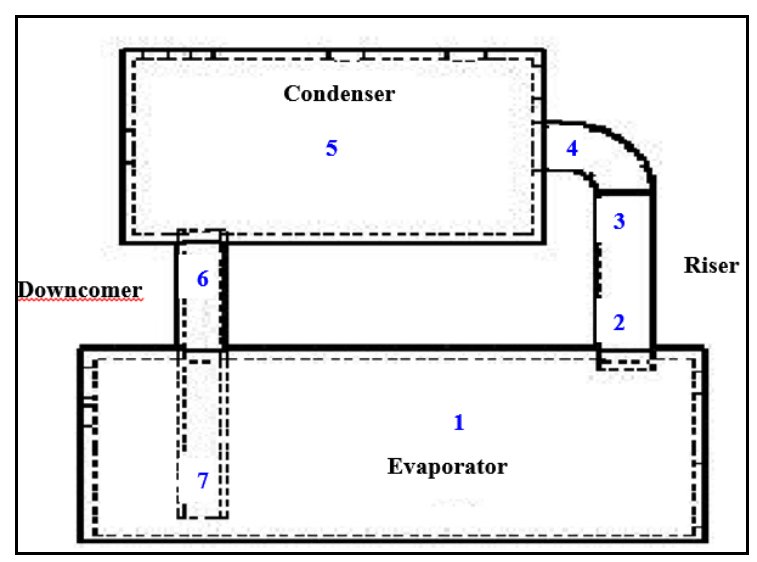

Fig.1. Schematic drawing of thermosyphon system.

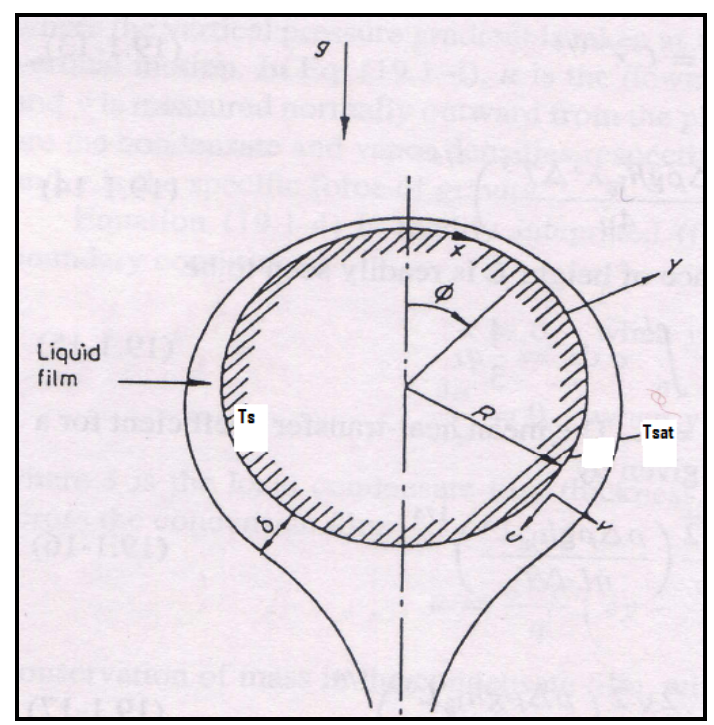

Fig.2. Schematic of film condensation in radial system. [1]

With the boundary conditions:

At $\mathrm{z}_{\mathrm{i}}=0, \mathrm{P}_{7}=\mathrm{P}_{\text {two-phase }}, \mathrm{P}_{2}=\mathrm{P}_{\mathrm{g} \text {,evaporator }}$

At $\mathrm{z}_{\mathrm{i}}=\mathrm{H}, \mathrm{P}_{6}=\mathrm{P}_{\mathrm{f} \text {,condenser }}, \mathrm{P}_{4}=\mathrm{P}_{\text {two-phase }}$

The condensation process is assumed as a film condensation in the radial tube (Fig.2), rather than dropwise condensation, as the surface of cooling coil where the condensation occurs is smooth, not rough. Thus the phenomena tend to be a film condensation.

Film condensation phenomena in thermosyphon water cooled condenser system occur at coolant coil surface. When R-113 vapor rises-up to the condenser section, in which water coolant with lower temperature $\left(T_{w i}\right)$ than the vapor temperature $\left(T_{s a t}\right)$ flows over the coolant coil, the temperature of R-113 vapor is reduced below its saturation temperature $\left(T_{\text {sat }}\right)$. The R-113 vapor then forms to R-113 liquid condensate. This liquid condensate covers the entire coolant coil outer surface, and under the action of gravity, the liquid continuously flows from the surface.

The governing equation for film condensation simulation:
Momentum balance: $\mu_{l} \frac{\partial^{2} u}{\partial y^{2}}+g \sin \theta \Delta \rho=0$

Conservation of mass: $\frac{\delta}{R} \frac{d}{d \theta}\left\{\int_{0}^{\delta} u d y\right\}=\frac{k_{l} \Delta T}{\rho h_{f g}}$

Energy balance:

$$
q=h_{f g} \Gamma=k_{l} \frac{\Delta T}{\delta}, \bar{q}=\frac{h_{f g}}{R} \frac{d \Gamma}{d \theta}=k_{l} \frac{d T}{d y}
$$

With boundary conditions:

$\mathrm{u}=0$ when $\mathrm{y}=0$; and when $\mathrm{y}=\delta, \frac{\partial u}{\partial y}=0$

At $\theta=0, \frac{d}{d \theta}\left\{\delta^{4} \frac{\rho \Delta \rho g h_{f g}}{\mu_{l} k_{l} d \Delta T}\right\}=0$

The detail derivations of film condensation characteristics are provided below which can explain the process occurs in thermosyphon system.

Assumptions:

1. The coolant coil surface is maintained at a constant temperature (Ts).

2. The saturation temperature of the quiescent vapor in which the surface is placed is Tsat.

\subsection{Fluid Mechanics Consideration}

Consider the schematic and fluid element shown. Assumption:

- Neglect inertia force

- Steady flow

- Viscous force and buoyancy force is balanced

Hence, the equilibrium equation of the fluid element:

$$
\begin{aligned}
& L_{c c} \delta x \delta y \rho_{l} g+P L_{c c}-(P+\delta P) L_{c c} \delta y \\
& -\tau_{x y} L_{c c} \delta x+\left(\tau_{x y}+\left[\frac{\partial \tau_{x y}}{\partial y}\right] \delta y\right) L_{c c} \delta x=0
\end{aligned}
$$

For the quiescent vapor: $\delta P=\delta x \rho_{v} g$

For a Newtonian fluid: $\tau_{x y}=\mu_{l} \frac{\partial u}{\partial y}$

Thus, by integrating for the velocity, the solution gives the velocity distribution as:

$$
u(y)=\frac{g\left(\rho_{l}-\rho_{v}\right) \sin \theta}{\mu_{l}}\left[\delta y-\frac{y^{2}}{2}\right]+C
$$

\section{1) Boundary condition}

At the coolant coil surface: $\mathrm{u}(0)=0$, thus $\mathrm{C}=0$. Hence, the velocity distribution becomes: 


$$
u(y)=\frac{g\left(\rho_{l}-\rho_{v}\right) \sin \theta}{\mu_{l}}\left[\delta y-\frac{y^{2}}{2}\right]
$$

2) Mass flow rate of condensate liquid

The liquid flow rate at a section of the film at a half side is given by:

$$
\left.\Gamma\right|_{1 / 2 \text { side }}=\int_{0}^{\delta} L_{c c} \rho_{l} u d y
$$

Substituting $\mathrm{u}(\mathrm{y})$ and then integrate, thus:

$$
\begin{gathered}
\left.\Gamma\right|_{1 / 2 \text { side }}=\frac{L_{c c} g\left(\rho_{l}-\rho_{v}\right) \rho_{l} \sin \theta}{\mu_{l}}\left[\frac{\delta^{3}}{3}\right] \\
\text { And thus, } \delta=\frac{L_{c c}^{1 / 3} \Gamma_{1 / 2}^{1 / 3} \mu_{l}^{1 / 3}}{\left[\rho_{l}\left(\rho_{l}-\rho_{v}\right) g \sin \theta\right]^{1 / 3}}
\end{gathered}
$$

3) Rate of condensation

The rate of condensation for the half side is defined as:

$$
\dot{m}_{c}=\frac{\partial \Gamma_{1 / 2}}{\partial x}, \text { where } \mathrm{x}=\mathrm{R} \theta
$$

4) Film condensation characteristic flow

The characteristic velocity to denote the flow of condensate film is:

$$
\begin{gathered}
u_{m}=\frac{\Gamma}{\left(\rho_{l} \delta L_{c c}\right)} \text { and } D_{h}=\frac{4 A}{p}=\frac{4\left(\delta \times L_{c c}\right)}{1}, \text { thus } \\
\operatorname{Re}_{\delta}=\frac{u_{m} D_{h} \rho_{l}}{\mu_{l}}=\frac{4 \Gamma}{\mu_{l}}
\end{gathered}
$$

Therefore, the flow characteristic of film condensation is as follow:

- $\mathrm{Re}_{\delta}<30$ is laminar flow

- $30<\mathrm{Re}_{\delta}<180$ is wavy flow

- $\mathrm{Re}_{\delta}>1800$ is turbulent flow

\subsection{Heat transfer consideration}

Assumptions:

- Velocity is small, so that convective energy transfer can be neglected

- Temperature gradient in the $\theta$ direction is also small

Energy balance for the small fluid element:

$$
q d x=\left[q+\frac{\partial q}{\partial y} d y\right] d x
$$

Hence, heat flux at the coolant coil surface is:

$$
\dot{Q}_{s}=-\left(\frac{k_{l}}{\delta}\right)\left(T_{s}-T_{s a t}\right) p_{2}
$$

Heat transfer coefficient is defined as:

$$
\dot{Q}_{s}=\bar{h}_{c} p_{2}\left(T_{s}-T_{s a t}\right)
$$

From (14) and (15):

$$
h_{c}=\left(\frac{k_{l}}{\delta}\right)
$$

is the expression for the laminar condensation heat transfer coefficient.

The energy balance:

$$
\Gamma h_{f}+h_{g} \dot{m}_{c} d x=(\Gamma+d \Gamma) h_{f}+\dot{Q}_{s} d x
$$

Using relation (11) and from (14):

$$
\Gamma_{1 / 2}=1.1438\left[\frac{g \rho_{l}\left(\rho_{l}-\rho_{v}\right)}{\mu_{l}{ }^{3}} \frac{k_{l}{ }^{3}\left(T_{s a t}-T_{s}\right)^{3} R^{3}}{h_{f g}{ }^{3}}\right]^{1 / 4}
$$

1) Average heat transfer coefficient and Nusselt number

Hence, for a tube where the condensate flows on both sides and representing the heat transfer rate by the heat transfer coefficient:

$$
\dot{Q}_{s}=2 \Gamma_{1 / 2} h_{f g}=2 \pi R \bar{h}_{c}\left(T_{s a t}-T_{s}\right) \quad, \quad \text { thus by }
$$

substituting equation (18), the average film condensation heat transfer coefficient is:

$$
\bar{h}_{c}=0.728\left[\frac{g \rho_{l}\left(\rho_{l}-\rho_{v}\right)}{\mu_{l}\left(T_{s a t}-T_{s}\right) D} \frac{k_{l}^{3} h_{f g}}{1 / 4}\right]^{1 / 4}
$$

Therefore, the average Nusselt number for a tube of diameter $2 \mathrm{R}$ becomes:

$$
\begin{aligned}
\overline{N u} & =\frac{\bar{h}_{c}(2 R)}{k_{l}} \\
& =0.728\left[\frac{g \rho_{l}\left(\rho_{l}-\rho_{v}\right)}{\mu_{l} k_{l}\left(T_{s a t}-T_{s}\right)} \frac{h_{f g} D^{3}}{{ }^{1 / 4}}\right.
\end{aligned}
$$

And heat transfer rate:

$$
\begin{aligned}
\dot{Q}_{s}= & 0.728 x\left[\frac{g \rho_{l}\left(\rho_{l}-\rho_{v}\right)}{\mu_{l}\left(T_{s a t}-T_{s}\right) D} \frac{k_{l}^{3} h_{f g}}{{ }^{\prime}}\right]^{1 / 4} \\
& x p_{2}\left(T_{s}-T_{\text {sat }}\right)
\end{aligned}
$$

2) Modified latent heat

The work by Rohsenow showed from experiments that the modified latent heat for condensation is given by [2]:

$$
h_{f g}^{\prime \prime}=h_{f g}[1+0.68 J a]
$$

Thus, the latent heat which is used in equation (19), (20) and (21) should be as modified latent heat. Hence average 
heat transfer coefficient, Nusselt number, and heat transfer rate becomes:

$$
\begin{aligned}
\bar{h}_{c}= & 0.728\left[\frac{g \rho_{l}\left(\rho_{l}-\rho_{v}\right)}{\mu_{l}\left(T_{s a t}-T_{s}\right) D} \frac{k_{l}{ }^{3} h_{f g}^{\prime \prime}}{{ }^{\prime} u}\right]^{1 / 4} \\
\overline{k_{l}} & \frac{\bar{h}_{c}(2 R)}{=} \\
\dot{Q}_{s}= & 0.728\left[\frac{g \rho_{l}\left(\rho_{l}-\rho_{v}\right)}{\mu_{l} k_{l}\left(T_{s a t}-T_{s}\right)} \frac{h_{f g}^{\prime \prime} D^{3}}{\mu_{l}\left(T_{s a t}-T_{s}\right) D}\right]^{1 / 4} \\
& x p_{2}\left(T_{s}-T_{s a t}\right)
\end{aligned}
$$

When using the above expression, all liquid properties are evaluated at the mean temperature between coolant coil surface and the saturated vapor $\left(T_{f}\right)$. Meanwhile, the vapor properties are evaluated at saturation vapor temperature (Tsat).

3) Heat transfer at coolant coil

Heat rate of water flowing in coolant coil is also meant heat dissipation.

$$
\begin{gathered}
d \dot{Q}_{d}=d \dot{Q}_{w}=\dot{m}_{w} C_{p, w} d T_{w} \\
\dot{Q}_{d}=\dot{Q}_{w}=\dot{m}_{w} C_{p, w} \int_{T_{w i}}^{T_{w o}} d T \\
\dot{Q}_{d}=\dot{Q}_{w}=\dot{m}_{w} C_{p, w}\left(T_{w o}-T_{w i}\right)
\end{gathered}
$$

The Nusselt number for water coolant inside the tube is given by:

$$
N u_{D}=0.023 \operatorname{Re}_{D}^{0.8} \operatorname{Pr}^{0.4}
$$

Furthermore, $N u=\frac{h_{w} D_{i}}{k_{w}}$, thus heat transfer coefficient for water coolant flow inside the tube is:

$$
h_{w}=\frac{k_{w}\left(0.023 \operatorname{Re}_{D}^{0.8} \operatorname{Pr}^{0.4}\right)}{D_{i}}
$$

4) Overall heat transfer coefficient

Heat transfer coefficient from R-113 vapor to water coolant is determined by overall heat transfer coefficient through the following equation:

$$
U=\frac{D i \times h_{w} \times h_{c}}{\left(D o \times \bar{h}_{c}\right)+\left(D i \times h_{w}\right)}
$$

Furthermore, heat transfer from coolant coil surface to water coolant is determined by:

$$
\dot{Q}_{w}=p_{1} h_{w}\left(T_{s}-T_{w}\right) \text {, }
$$

Hence, it is necessary to define Tw which is mean temperature of water coolant $(\mathrm{Tm})$. Thus the heat transfer becomes:

$$
\dot{Q}_{w}=p_{1} h_{w}\left(T_{s}-T_{m}\right)
$$

\section{Result and Discussion}

\subsection{Validation}

There is a good agreement between experimental and simulation results (Fig.3 and Fig.4).

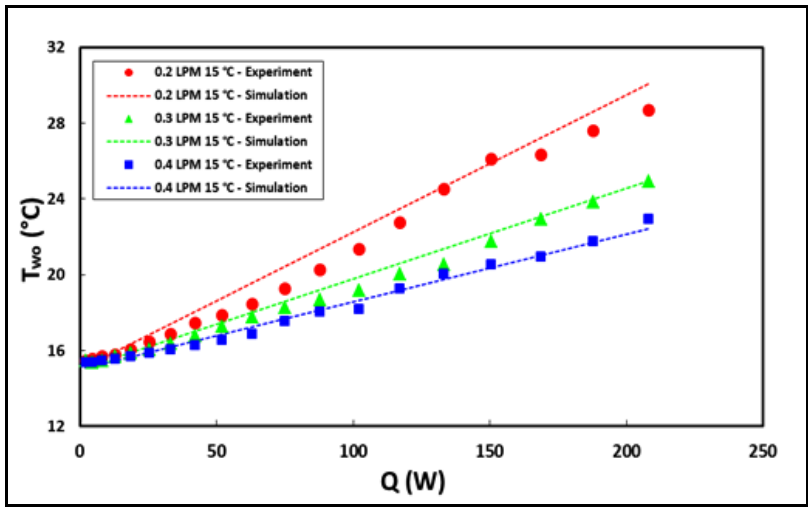

Fig.3. Validation of outlet water temperature at a constant $T_{w i}$ of $10{ }^{\circ} \mathrm{C}$

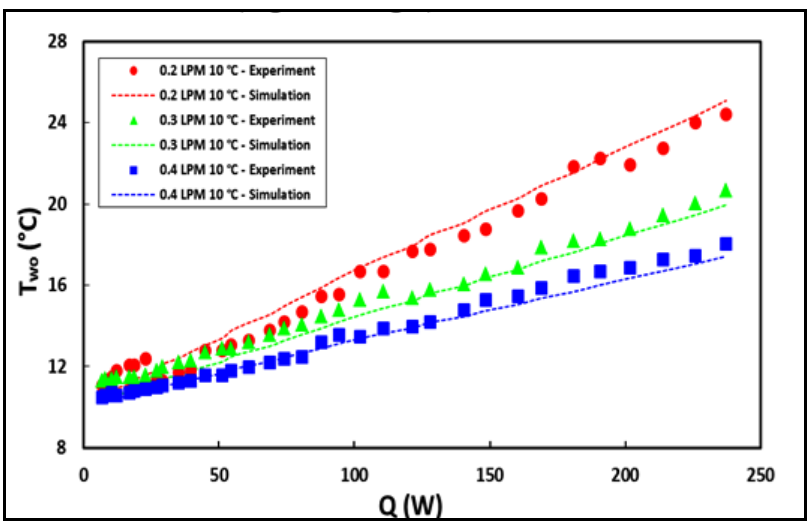

Fig.4. Validation of outlet water temperature at a constant $T_{w i}$ of $15{ }^{\circ} \mathrm{C}$

Furthermore, for $0.3 \mathrm{LPM} 10{ }^{\circ} \mathrm{C}$, it is found the standard deviation of $0.3 \%$. This small standard deviation indicates the good accuracy of the simulation.

\subsection{Units Effect of the water mass flow rate $\left(m_{\mathrm{w}}\right)$ and inlet water temperature $\left(T_{\text {wi }}\right)$ on film condensation rate $(\Gamma)$ Effect of $\mathrm{NaOH}$ Concentration to Biodiesel Yield}

Effect of the inlet water temperature on film condensation rate $(\Gamma)$ is presented in Fig. 5, 6 and 7. These figures firstly explained that at constant $m_{w}$, the higher inlet water temperature would result in higher Nusselt number of water. Furthermore, at the same Nusselt number of water, the lower inlet water temperature obtained a higher film condensation rate. 


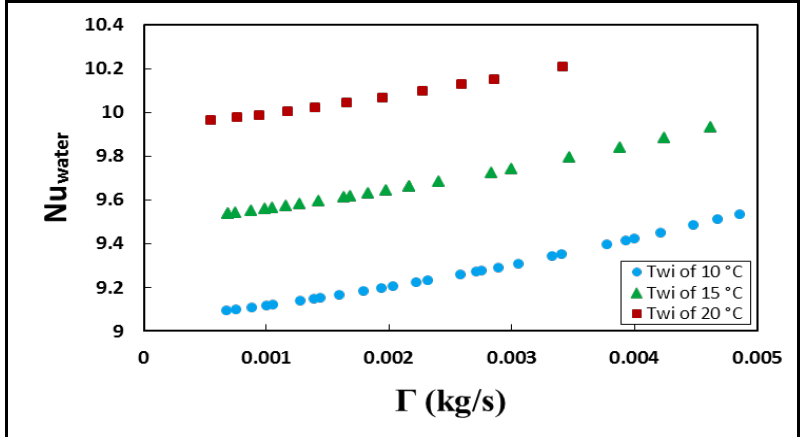

Fig.5. Effect of inlet water temperature on film condensation rate at constant alidation of outlet water temperature at a constant $m_{w}$ of $0.0033 \mathrm{~kg} / \mathrm{s}$.

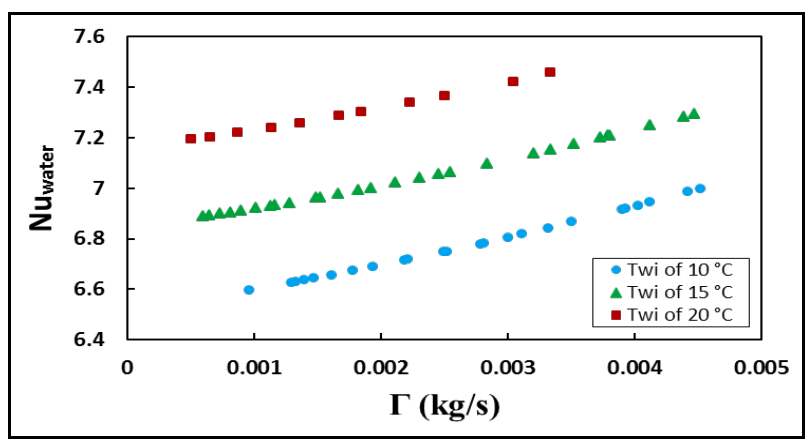

Fig.6. Effect of inlet water temperature on film condensation rate at constant alidation of outlet water temperature at a constant $m_{w}$ of $0.005 \mathrm{~kg} / \mathrm{s}$.

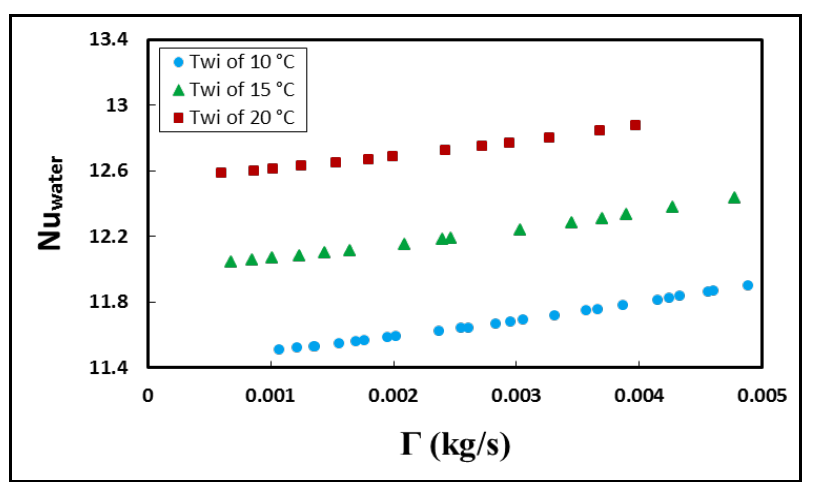

Fig.7. Effect of inlet water temperature on film condensation rate at constant alidation of outlet water temperature at a constant $m_{w}$ of $0.0067 \mathrm{~kg} / \mathrm{s}$.

Figures 8, 9, and 10 present the effect of the mass flow rate of inlet water on film condensation rate. It can be noticed that Reynold number of water increased as the mass flow rate of inlet water increased. Moreover, it also can be noticed that the larger Reynold number will increase the film condensation rate.

In the present study, it can be concluded that the Nusselt number of water is 6.5-12.87, Reynold number of water is 389 to 1069.3 , and film condensation rate is $0.0005 \mathrm{~kg} / \mathrm{s}$ to $0.0048 \mathrm{~kg} / \mathrm{s}$.

This study assumed that the condensation process formed only as film condensation and dropwise condensation was not considered. This is due to the fact that the condenser tube surface is smooth, which tends to favour film condensation. Nevertheless, the results are significant to provide condensation characteristics of thermosyphon cooling systems.

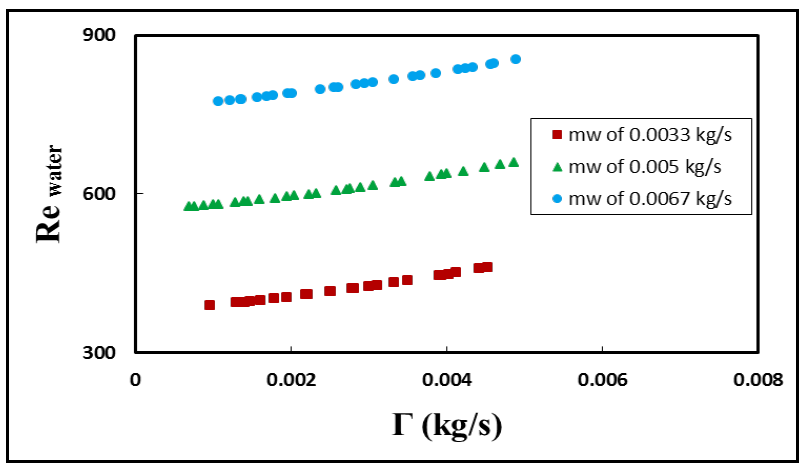

Fig.8. Effect of mass flow rate of water on film condensation rate at a constant $T_{w i}$ of $10^{\circ} \mathrm{C}$.

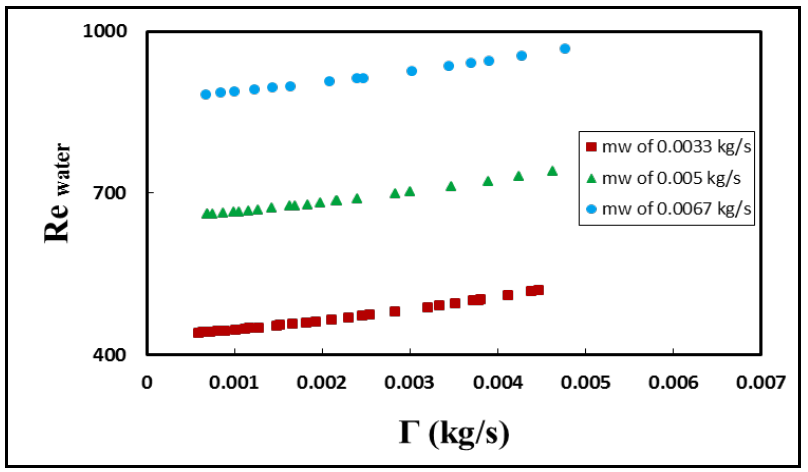

Fig.9. Effect of mass flow rate of water on film condensation rate at a constant $T_{w i}$ of $15^{\circ} \mathrm{C}$.

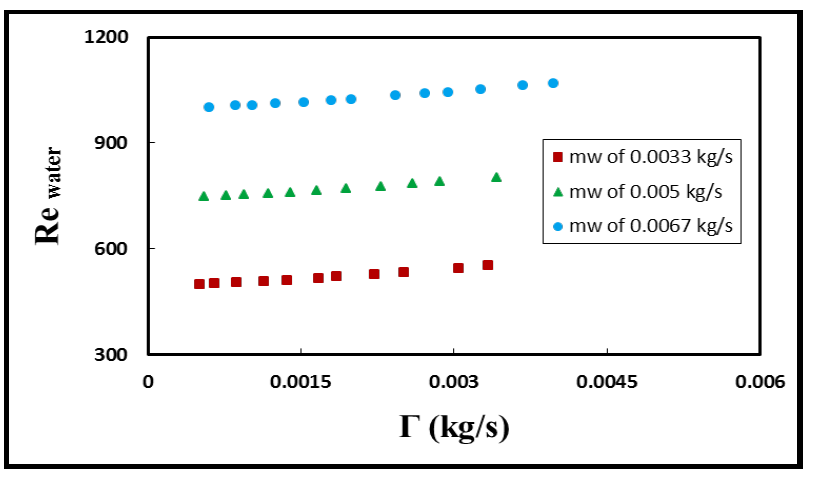

Fig.10. Effect of mass flow rate of water on film condensation rate at a constant $T_{w i}$ of $20^{\circ} \mathrm{C}$.

\subsection{Effect of the Water Mass Flow Rate $\left(m_{w}\right)$} and Inlet Water Temperature $\left(T_{w i}\right)$ on Nusselt Number Film Condensation $\mathrm{Nu}$ )

Figures 11, 12, and 13 show that Nusselt number of film condensation increases as the Nusselt number of water decreases at the various constant of $m_{w}$. Additionally, the lower temperature $T_{w i}$ will result in lower Nusselt number of water. It may be observed that higher Nusselt number of film condensation is obtained with by flow of lower $T_{w i}$. 


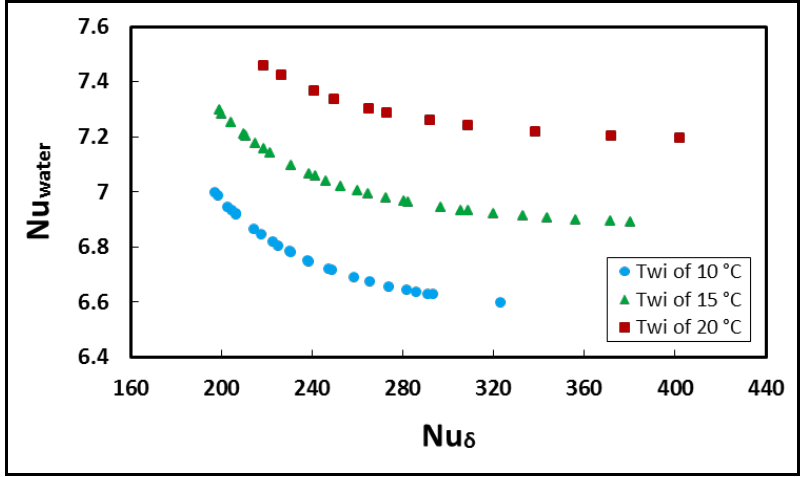

Fig.11. Effect of inlet water temperature on the Nusselt number of film condensation at a constant $\dot{m}_{w}$ of $0.0033 \mathrm{~kg} / \mathrm{s}$.

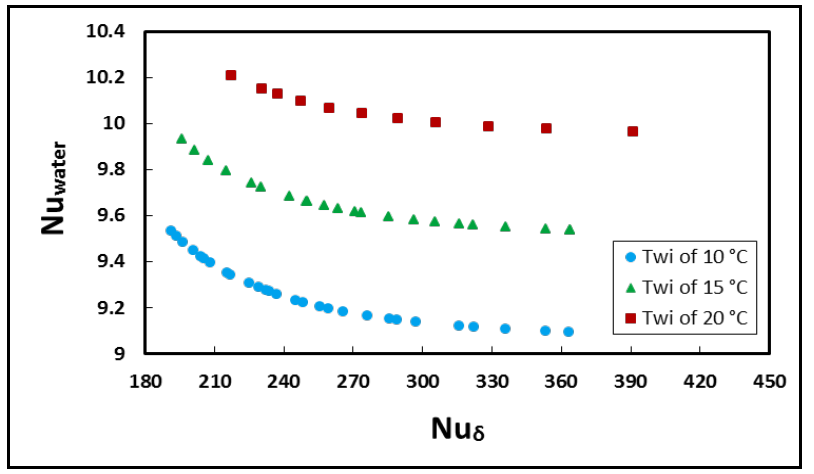

Fig.12. Effect of inlet water temperature on the Nusselt number of film condensation at a constant $m_{w}$ of $0.005 \mathrm{~kg} / \mathrm{s}$.

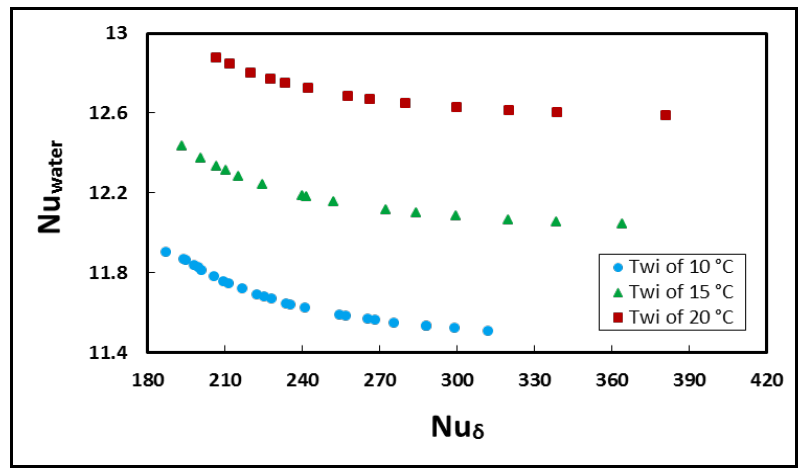

Fig.13. Effect of inlet water temperature on the Nusselt number of film condensation at a constant $m_{w}$ of $0.0067 \mathrm{~kg} / \mathrm{s}$.

The effect of the water mass flow rate $\left(m_{w}\right)$ on Nusselt number film condensation $(\mathrm{Nu})$ at various constant $T_{w i}$ can be shown in Fig. 14, 15 and 16. It can be noticed that the higher Nusselt number film condensation can be gained by lower Reynold number of water. In addition, the lower Reynold number of water can be gained by flowing lower mass low rate of inlet water. Hence, the lower mass low rate of inlet water will result in higher Nusselt number film condensation. This result is in conflict with the requirement of achieving high cooling capacity and large film condensation rate. It explains that an increase in the film condensation rate, which represents an increase in the thickness of the film, causes a slight reduction of the average convection coefficient. This slight reduction in the average convection coefficient, therefore, obtains a lower Nusselt number of film condensation. These results, which are in dimensionless number forms, provide significant data which are applicable for any geometry of cooling systems. However, this study was limited to water as an external coolant.

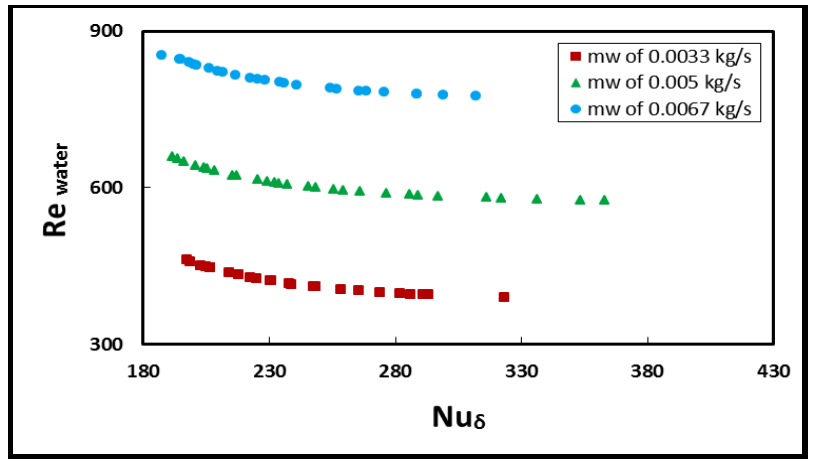

Fig.14. Effect of mass flow rate of inlet water on the Nusselt number of film condensation at a constant $T_{w i}$ of $10{ }^{\circ} \mathrm{C}$.

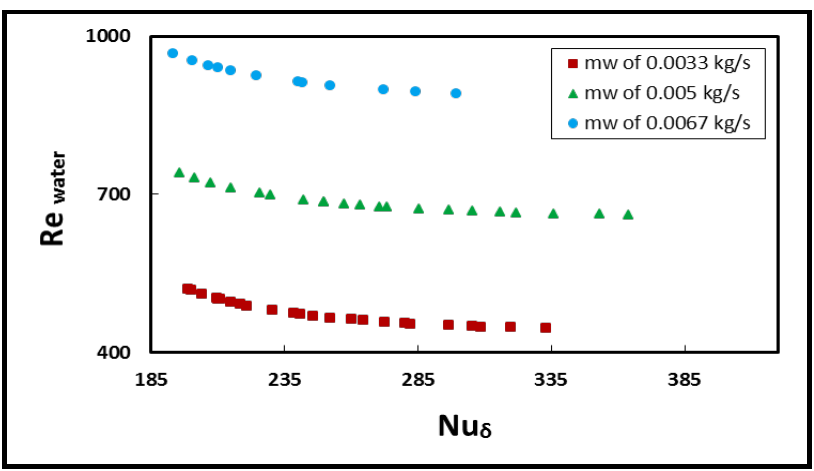

Fig.15. Effect of mass flow rate of inlet water on the Nusselt number of film condensation at a constant $T_{w i}$ of $15^{\circ} \mathrm{C}$.

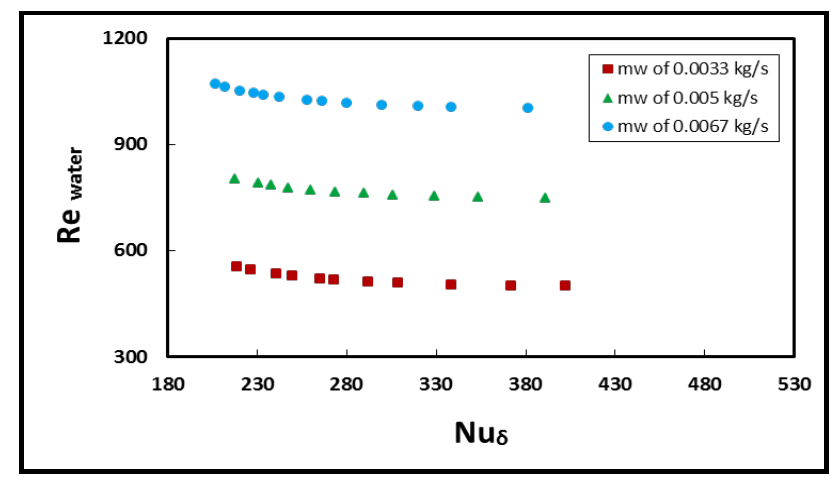

Fig.16. Effect of mass flow rate of inlet water on the Nusselt number of film condensation at a constant $T_{w i}$ of $20^{\circ} \mathrm{C}$.

\subsection{Effect of the Water Mass Flow Rate $\left(m_{w}\right)$ and Inlet Water Temperature $\left(T_{w i}\right)$ on Reynold Number Film Condensation $\left(\mathrm{Re}_{\delta}\right)$}

The flow regime of film condensation is determined by the Reynold number. For laminar flow, $\mathrm{Re}_{\delta}<30$; for wavy-transition, $30 \leq \mathrm{Re}_{\delta} \leq 1800$; and for turbulent flow, $\mathrm{Re}_{\delta}>1800$ [3]. 
The film condensation layer in the present study is in the laminar and wavy-transition regime. It can be seen from Fig. 17-22 that the $\mathrm{Re}$ is $3.9 \leq \mathrm{Re}_{\delta} \leq 29$ for the laminar regime and $30 \leq \mathrm{Re}_{\delta} \leq 40$ for the wavy-transition regime. It is found by flowing inlet water temperature of $20{ }^{\circ} \mathrm{C}$ with the mass flow rate of $0.0033 \mathrm{~kg} /$ and 0.005 $\mathrm{kg} / \mathrm{s}$ will result in laminar regime. Inlet water temperature of $20{ }^{\circ} \mathrm{C}$ and mass flow rate of $0.0067 \mathrm{~kg} / \mathrm{s}$ has a laminar regime in the range heat flux of $0.37 \mathrm{~W} / \mathrm{cm}^{2}-2.97$ $\mathrm{W} / \mathrm{cm}^{2}$. The detailed heat flux range $\left(\mathrm{W} / \mathrm{cm}^{2}\right)$ for laminar and wavy-transition regime can be seen in Table 1:

Table 1. Heat Flux Range For Laminar and Wavy-Transition Regime

\begin{tabular}{|c|c|c|c|}
\hline \multirow{3}{*}{$\begin{array}{c}m_{w} \\
\mathrm{~kg} / \mathrm{s})\end{array}$} & $\begin{array}{c}T_{w i} \\
\left({ }^{\circ} \mathrm{C}\right)\end{array}$ & $\begin{array}{c}\text { Laminar } \\
\left(\mathrm{W} / \mathrm{cm}^{2}\right)\end{array}$ & $\begin{array}{c}\text { Wavy-transition } \\
\left(\mathrm{W} / \mathrm{cm}^{2}\right)\end{array}$ \\
\hline \multirow{3}{*}{0.0033} & 10 & $0.7-3.37$ & $3.62-4.74$ \\
\cline { 2 - 4 } & 15 & $0.37-3.2$ & $3.37-4.74$ \\
\cline { 2 - 4 } & 20 & All range & - \\
\hline \multirow{3}{*}{0.005} & 10 & $0.46-3.2$ & $3.37-4.74$ \\
\cline { 2 - 4 } & 15 & $0.37-3.37$ & $3.62-4.74$ \\
\cline { 2 - 4 } & 20 & All range & - \\
\hline & 10 & $0.7-3.2$ & $3.37-4.74$ \\
\cline { 2 - 4 } & 15 & $0.37-2.97$ & $3.2-4.74$ \\
\cline { 2 - 4 } & 20 & $0.37-2.97$ & $3.2-4.74$ \\
\hline
\end{tabular}

It also can be noticed that the value of Reynold number film condensation increases as the Nusselt number of water increase as can be seen in Fig. 17, 18, and 19. It also can be seen that at various constant mass flow rates of the water, at the same Nusselt number of water, the Reynold number of film condensation increases with lower inlet water temperature. Therefore, it can be observed that lower inlet water temperature increases the value of Reynold number of film condensation leading to more wavy and turbulent flow.

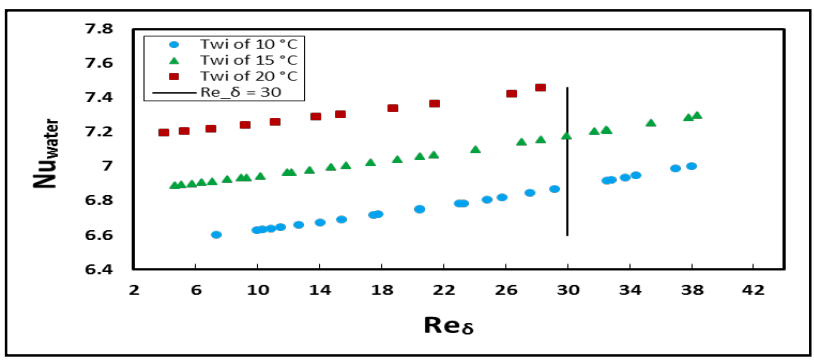

Fig. 17. Effect of inlet water temperature on the Reynold number of film condensation at a constant $m_{w}$ of $0.0033 \mathrm{~kg} / \mathrm{s}$.

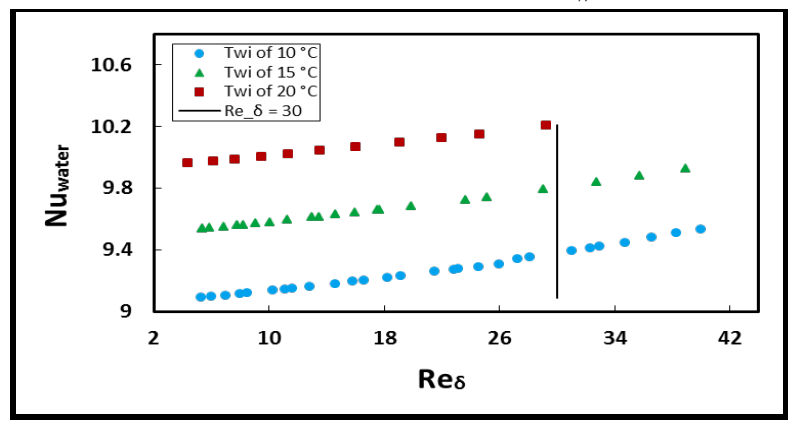

Fig. 18. Effect of inlet water temperature on the Reynold number of film condensation at a constant $m_{w}$ of $0.005 \mathrm{~kg} / \mathrm{s}$.

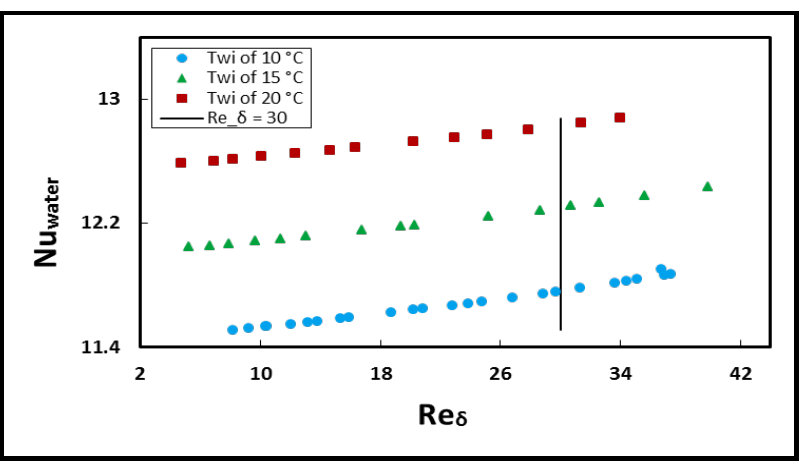

Fig. 19. Effect of inlet water temperature on the Reynold number of film condensation at a constant $m_{w}$ of $0.0067 \mathrm{~kg} / \mathrm{s}$.

Figures 20, 21, and 22 show that the values of Reynold number of film condensation increase as the Reynold numbers of water increase. In addition, the higher mass flow rate of water will result in higher Reynold number of water. Therefore, it also can be noticed that greater $m_{w}$ increases the value of Re which also leads to more wavy and turbulent flow.

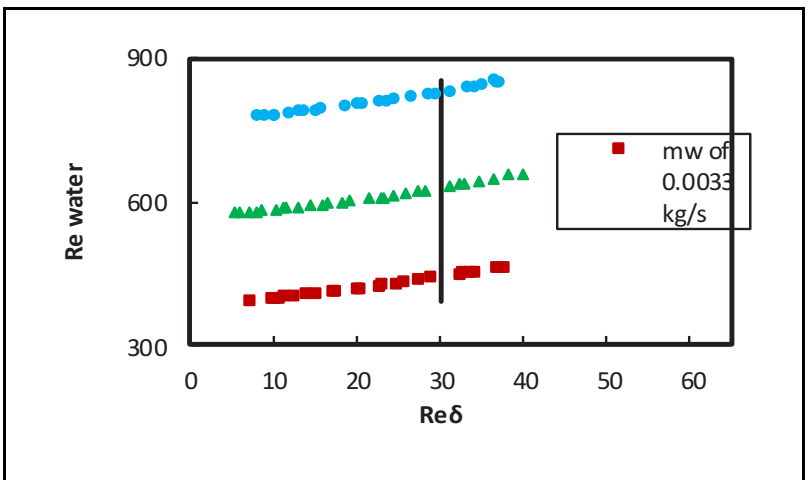

Fig. 20. Effect of mass flow rate of inlet water on Reynold number of film condensation at constant $T_{w i}$ of $10^{\circ} \mathrm{C}$.

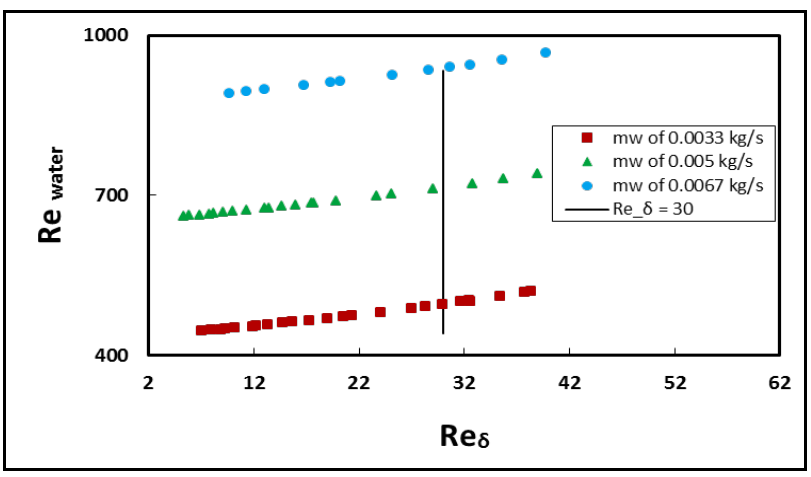

Fig. 21. Effect of mass flow rate of inlet water on the Reynold number of film condensation at a constant $T_{w i}$ of $15^{\circ} \mathrm{C}$. 


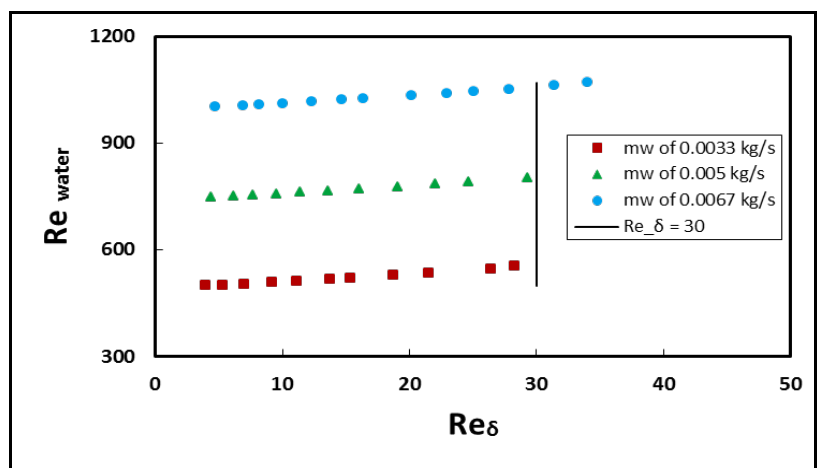

Fig. 22. Effect of mass flow rate of inlet water on the Reynold number of film condensation at a constant $T_{w i}$ of $20^{\circ} \mathrm{C}$.

\section{Conclusion}

The study was conducted both numerical and experimental investigation. There is a reasonable agreement between numerical predictions and experimental data owing to the small standard deviation of $0.3 \%$.

The results of the present study, which is in dimensionless number forms (Reynold and Nusselt number), provide significant data which are applicable for any geometry of cooling systems. Even though this study was limited to water only as an external coolant, the present study can be used as a guideline for thermal management engineers to design and fabricate a compact cooling system.

\section{References}

[1] F. Arbiyani, ARPN Journal of Engineering and Applied Sciences 11, 4016-4021, (2016)

[2] F.P. Incropera, D.P. Dewitt, T.L. Bergman, A.S. Lavine, Fundamentals of Heat and Mass Transfer Sixth edition, 645-652 (John Wiley and Sons (Asia), Singapore, 2007)

[3] S.G. Kandlikar, M. Shoji, V.K. Dhir, Handbook of Phase Change: Boiling and Condensation, (Taylor\&Francis, Philadelphia, 1999) 